\title{
Factors Influencing Utilization of Child Immunization Services in a Tertiary Health Institution in Sokoto North-West Nigeria
}

\author{
Oluwole Victor Oluwalomola ${ }^{1}$, Ebenezer Obi Daniel ${ }^{1, ~ *}$, Paul Olaiya Abiodun ${ }^{1}$, \\ Israel Olukayode Popoola ${ }^{2}$, Kabir Yunusa Amari ${ }^{3}$, Ahmed Mamuda Bello ${ }^{1}$, \\ Christie Omolola Adams ${ }^{1}$, Olayinka Victor Ojo ${ }^{1}$ \\ ${ }^{1}$ Department of Public Health, School of Public Health, Texila American University, Georgetown, Guyana South America \\ ${ }^{2}$ Department of Epidemiology and Community Health, Faculty of Clinical Sciences, College of Medicine, University of Ilorin, Ilorin, Nigeria \\ ${ }^{3}$ Department of Psychology, Faculty of Arts, Benue State University, Makurdi, Nigeria
}

Email address:

dannypressy@yahoo.com (E. O. Daniel)

${ }^{*}$ Corresponding author

\section{To cite this article:}

Oluwole Victor Oluwalomola, Ebenezer Obi Daniel, Paul Olaiya Abiodun, Israel Olukayode Popoola, Kabir Yunusa Amari, Ahmed Mamuda Bello, Christie Omolola Adams, Olayinka Victor Ojo. Factors Influencing Utilization of Child Immunization Services in a Tertiary Health Institution in Sokoto North-West Nigeria. International Journal of Immunology. Vol. 8, No. 2, 2020, pp. 25-32. doi: $10.11648 /$ j.iji.20200802.13

Received: May 6, 2020; Accepted: May 22, 2020; Published: June 3, 2020

\begin{abstract}
Despite our hygiene and safety some infections can still spread hence the need for vaccination and immunization of people especially during childhood. The high effectiveness of immunization in preventing diseases and death as made immunization one of public health's most cost-effective intervention. When parents fail or do not complete their child's vaccination, diseases that are long gone might re-appear. This study aimed at determining the knowledge, attitude and practice of mothers/guide towards immunization and the factors affecting utilization of immunization services in a tertiary institution in North-West Nigeria. One hundred and thirty-eight mothers/guides participated in this cross-sectional study. Respondents were recruited using a purposive sampling technique. A 47-item questionnaire on the self-reported knowledge, attitudes and practices towards utilization of immunization services was formulated and used for data collection. A focus group discussion which involved three vaccination health workers working in the health facility was also carried out in the study. A large proportion of the participants are within the age group of 21-30 (60.14\%). Those who had no formal education, 53 (38.41\%) were the majority. This study revealed that $93 \%$ have poor knowledge while $7 \%$ have good knowledge about immunization. $57.97 \%$ have good attitudes and $42.03 \%$ have poor attitude towards immunization. $52.90 \%$ have good practices while $47.10 \%$ have poor practices towards immunization. Level of education was revealed to have statistical significant relationship with mothers/guides knowledge, attitude and practice towards immunization. Factors such as lack of husbands' consent, absence from town, sick child, travel cost and travel distance were reported to affect utilization of immunization services. According to the outcome of this study, it implies that a high proportion of mothers/guides have poor knowledge about immunization. Efforts should be made to appropriately educate mothers/guides on various vaccine preventable diseases and appropriate immunization schedules to ensure better compliance. Lack of husband's consent is a major factor that affects the utilization of child immunization services by mothers/guides. Therefore, efforts should be targeted at educating men and employ necessary campaigns to change gender discrimination in relationships and households in this part of Nigeria.
\end{abstract}

Keywords: Vaccination, Immunization, Knowledge, Attitude, Practice, Utilization 


\section{Introduction}

Despite our hygiene and safety some infections can still spread hence the need for vaccination and immunization of people especially during childhood. The high effectiveness of immunization in preventing diseases and death as made immunization one of public health's most cost-effective intervention. The two most important public health interventions that constitute a cost effective strategy to reduce both the morbidity and mortality associated with infectious diseases are immunization and vaccination [1]. When we fail or do not complete our vaccination diseases that are long gone might re-appear.

Through vaccination a variety of diseases, disability and death from infectious diseases have been eliminated or reduced by $90 \%$. Vaccination has also brought great net economic benefit to the society. Vaccines do not provide individual protection for those persons who are vaccinated only, but they can also provide community protection by reducing the spread of disease within a population [2].

Although majority of parents have increased knowledge on the importance of child immunization and have gotten their children immunized but there have also been difficulties encountered by some parents in accessing health facilities in order to receive these vaccinations for their children. Some were incompletely vaccinated during the period necessary for vaccination for protection from future exposures to pathogens that could cause debilitating ailments but could have been prevented if they were completely vaccinated. Due to cultural misconceptions on the cause of diseases and mistrust in the safety and efficacy of vaccines large number of children have been left unvaccinated especially in Northern Nigeria [3]. The World Health Organization reported that about 19.9 million infants globally did not receive vaccination in the year 2017 .

In 1974, the Expanded Program on Immunization (EPI) was established by the World Health Organization to ensure access of routinely recommended vaccines to all children globally. While there has been a global coverage of certain vaccines, however more than one-fifth of children globally still are not fully vaccinated especially in low-income countries. A publication by WHO in 2012 reported that Nigeria is part of the 3 countries where more than half of incompletely vaccinated children lives [4].

In 1978, the Expanded Programme on Immunization (EPI) was introduced with the aim of providing routine immunization to children less than the age of two years, this recorded initial but intermittent success in Nigeria. There have been gradual but consistent reductions in immunization coverage in Nigeria [1].

As such, in this part of the world attention should not only be focused on factors affecting under-vaccination (immunization coverage) only but it should also be centered on non-vaccination (immunization utilization) and the validity of the vaccine (immunization efficacy).

Routine childhood immunization is important to both individual and public health. It is strongly promoted by the
World Health Organization and by governments, public health authorities, and health professions worldwide [5].

Due to the continuous worries about the safety and efficacy of vaccines, and whether immunization programs are still needed, there have been significant minority of parents who refuse vaccination [6].

The organizational segment of ministries of health charged with preventing diseases, disability and death from vaccinepreventable diseases in children and adults is the National Immunization Programme. As directed by the federal ministry of health, a child is said to be fully vaccinated after receiving the following vaccines at the due dates:

1) BCG (Bacilli Calmette Guerin)

2) OPV (Oral Polio Vaccine)

3) DPT (Diphtheria, pertusis, tetanus)

4) Hepatitis B

5) Measles

6) Yellow Fever

7) Vitamin A

These vaccinations are to be received within the first year of life including doses received at birth. To get a complete vaccination it requires five visits to the immunization clinic. By age 12-23 months children would have been completely vaccinated and are therefore fully immunized against Tuberculosis, Diphtheria, whooping cough, polio, tetanus, hepatitis and measles.

The northern Nigeria is part of those places in the world with the lowest immunization rate [1]. The 2003 National Immunization Schedule reported the percentage of fully immunized infants in the targeted states was less than $1 \%$ in Jigawa, $1.5 \%$ in Yobe, $1.6 \%$ in Zamfara and $8.3 \%$ in Katsina. Thousands of children are therefore victims of vaccinepreventable diseases. They also reported factors such as misperception of routine immunization, influence of religion, political problems etc. as some factors affecting routine immunization in Nigeria.

Maternal level of education, accessibility to health facility, sick guardian/sick child, conflicting priorities, religion and attitude of health workers are some of the factors that also contribute to missed opportunities and incomplete vaccination [7].

The advent of combination vaccines significantly reduced the volume of immunization activities by decreasing the number of injections, amount of pain and cumulative exposure to preservatives and stabilizers that may contribute to adverse events.

The attitudes and beliefs of vaccinators or immunization providers toward immunization have the potential to improve educational efforts and behavioral change [8]. Some vaccinators has been reported to lack conviction about vaccination, this has led Dionne to make recommendation that "public health authorities should target systematic interventions towards vaccinators to improve this situation and to increase nurses' conviction regarding the benefits of vaccination" [9].

It was reported that vaccinators who were respondents in the study had overall confidence in vaccines but had specific 
concerns about the number of vaccines given to children and vaccine content [10]. Therefore, these unfounded concerns may reduce parental confidence in immunization.

In a study of the opinion of Quebec parents and vaccinators on the usefulness of chicken pox vaccine, it was reported that "there was not great enthusiasm for this vaccine among vaccinators [11], barely half of the pediatricians considered the vaccine to be useful, while a clearly smaller proportion (33\%) of nurses found it to be useful".

\section{Method}

This study was a cross sectional descriptive study. The study was conducted in Usman Dan Fodio University Teaching Hospital. The department of community medicine of this facility provides routine immunization service for children in the state and also has a catchment area of neighboring states. The participants of this study were care givers (mothers and guardians) of infants and children attending immunization clinic of the facility and also vaccination health workers who have worked in the hospital for at least one year. They were selected through purposive sampling method.

Data for this study were collected using a structured questionnaire for the mothers/guides while a Focus Group Discussion (FGD) was conducted for the vaccination health workers. The questionnaire for the mothers/guides consisted of four sections viz: Section A consists of socio-demographic variables, section B consists of questions on knowledge of mothers/guardians on immunization; section $\mathrm{C}$ consists of questions on attitude of mothers/guardians towards immunization and section D consist of practice, beliefs, perception towards immunization. The FGD for the vaccination health workers was effective to explore their opinions and experiences. Through the FGD vaccination health workers were able to express their opinions better which might not be possible through administering of questionnaires. Two research assistants were recruited and trained for the purpose of data collection and language interpretation was done for all mothers/guides who could not read English.

Ethical approval was obtained from the Health Research and Ethics Committee of the hospital (UDUTH). Each Participant was informed in writing, with full explanation of the content of the questionnaire and the purpose of the study. They were assured the confidentiality of whatever information given by them for the study.

Collected data was analyzed using SPSS software. Descriptive statistics were used to summarize data into frequencies, graphs and tables. Chi-square was used to test for association between various socio-demographic factors and knowledge and attitude of mothers/guardians.

\section{Results}

Socio-demographic Characteristics of Participants

A large proportion of the participants are within the age group of $21-30(60.14 \%)$. Approximately $94 \%$ of them are married while Islam religion $111(80.43 \%)$ is practiced by majority of the participants. Those who had no formal education, $53(38.41 \%)$ were the majority followed by those with a formal education to the tertiary level 47 (34.06\%). Occupational distributions showed that a little below half of the participants are house wives $68(49.28 \%)$, followed by those carrying out business activities 36 (26.09\%) and those working in health care with the lowest 5 (3.62\%). A considerable proportion of respondents have at least two children 38 (26.9\%), and $35(25.4 \%)$ have three children.

Table 1. Socio-demographic characteristics of mothers/guides.

\begin{tabular}{|c|c|c|}
\hline VARIABLE & FREQUENCY & PERCENTAGE \\
\hline \multicolumn{3}{|l|}{ Age } \\
\hline $15-20$ & 5 & $3.62 \%$ \\
\hline $21-30$ & 83 & $60.14 \%$ \\
\hline $31-40$ & 46 & $33.33 \%$ \\
\hline $41-50$ & 2 & $1.45 \%$ \\
\hline Missing & 2 & $1.45 \%$ \\
\hline TOTAL & 138 & $100 \%$ \\
\hline \multicolumn{3}{|l|}{ Marital Status } \\
\hline Single & 6 & $4.35 \%$ \\
\hline Married & 130 & $94.20 \%$ \\
\hline Divorced & 1 & $0.72 \%$ \\
\hline Missing & 1 & $0.72 \%$ \\
\hline TOTAL & 138 & $100.00 \%$ \\
\hline \multicolumn{3}{|l|}{ Religion } \\
\hline Christian & 24 & $17.39 \%$ \\
\hline Islam & 111 & $80.43 \%$ \\
\hline Missing & 3 & $2.17 \%$ \\
\hline TOTAL & 138 & $100.00 \%$ \\
\hline \multicolumn{3}{|c|}{ Level of Education: } \\
\hline None & 53 & $38.41 \%$ \\
\hline Primary & 5 & $3.62 \%$ \\
\hline Secondary & 30 & $21.74 \%$ \\
\hline Tertiary & 47 & $34.06 \%$ \\
\hline Missing & 3 & $2.17 \%$ \\
\hline TOTAL & 138 & $100.00 \%$ \\
\hline \multicolumn{3}{|l|}{ Occupation: } \\
\hline House Wife & 68 & $49.28 \%$ \\
\hline Farming & 6 & $4.35 \%$ \\
\hline Teaching & 20 & $14.49 \%$ \\
\hline Health Care & 5 & $3.62 \%$ \\
\hline Business & 36 & $26.09 \%$ \\
\hline Missing & 3 & $2.17 \%$ \\
\hline TOTAL & 138 & $100.00 \%$ \\
\hline \multicolumn{3}{|c|}{ Number of Children } \\
\hline One & 25 & 18.1 \\
\hline Two & 38 & 27.5 \\
\hline Three & 35 & 25.4 \\
\hline Four & 15 & 10.9 \\
\hline Five & 10 & 7.2 \\
\hline Six & 4 & 2.9 \\
\hline Seven & 6 & 4.3 \\
\hline Eight & 4 & 2.9 \\
\hline Missing System & 1 & .7 \\
\hline TOTAL & 138 & 100.0 \\
\hline
\end{tabular}

Knowledge of Mothers/Guides on Immunization

The knowledge distribution of the mothers/guide that come for immunization services in Usman Dan Fodio Teaching Hospital, Sokoto is represented by figure 1. About ninety-three per cent $(93 \%)$ have poor knowledge while approximately seven (7\%) have good knowledge about immunization. 


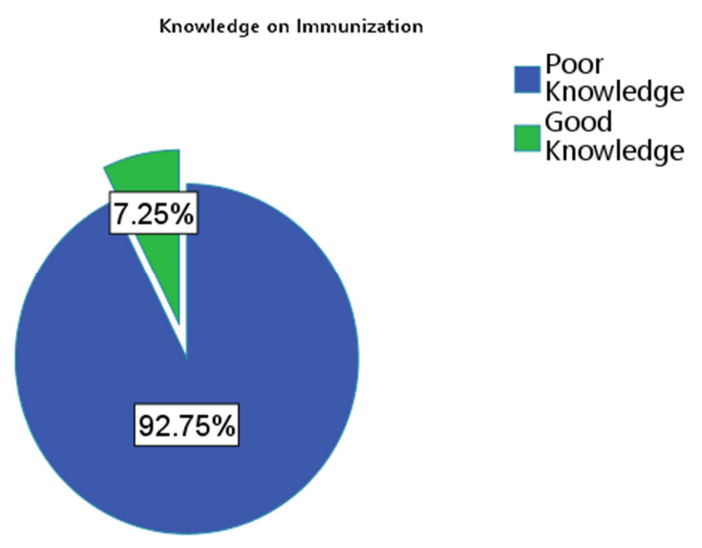

Figure 1. Knowledge of mothers/guide towards immunization.

Attitudes of Mothers/Guides towards Immunization

A little above half of the respondents (57.97\%) have good attitudes and $42.03 \%$ have poor attitude towards immunization. This is shown in the attitude percentage distribution of the respondents in figure 2 .

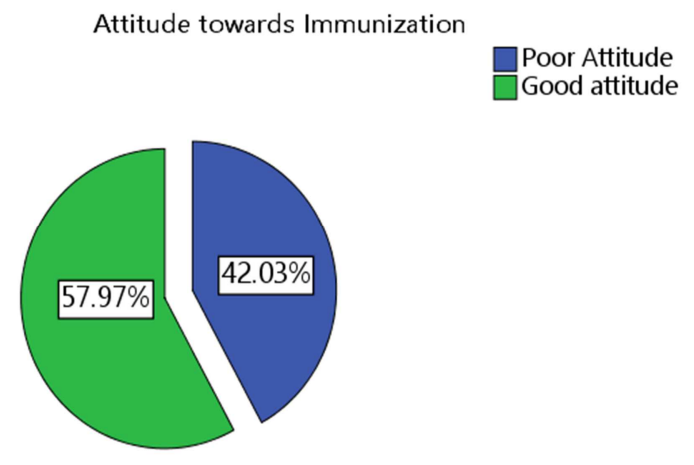

Figure 2. Attitude of mothers/guide towards immunization.

Practice of Mothers/Guides towards Immunization

Figure 3 below shows the practice percentage distribution of the respondents, it showed that slightly above half of the respondents have good practices (52.90\%) while $47.10 \%$ have poor practices towards immunization.

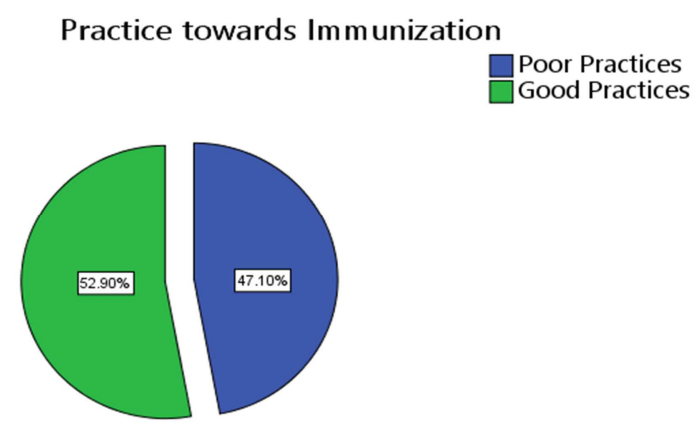

Figure 3. Practice of mothers/guide towards immunization.

Association between Mothers'/Guides' Knowledge and Socio-demographic Variables

Table 2 shows the association between the knowledge and the socio-demographic variables of the respondents. Only two of the socio-demographic variables, which are age and level of education were found to have statistically significant relationship with the knowledge of the mothers/guides on immunization $(\mathrm{P}<0.05)$.

Table 2. Chi-Square analysis showing association between mothers'/guides' knowledge on immunization and socio-demographic characteristics of the respondents.

\begin{tabular}{llll}
\hline & $\chi^{2}$ value & Df & p value \\
\hline Age & 10.337 & 3 & $0.016^{* *}$ \\
Marital Status & 0.581 & 2 & 0.748 \\
Religion & 0.036 & 1 & 0.849 \\
Level of Education & 14.813 & 3 & $0.002 * *$ \\
Occupation & 6.439 & 4 & 0.169 \\
Number of Children & $11.810^{\mathrm{a}}$ & 7 & 0.107 \\
\hline
\end{tabular}

** Significant at $\mathrm{P}<0.05$

Knowledge on Diseases that could be Prevented by Immunization

The respondents' knowledge on diseases that immunization can prevent was evaluated in this study. Results in Table 3 below, showed that 122 (90.3\%), 80 $(60.1 \%)$ felt that immunization can prevent their children from having malaria and typhoid respectively. While 68 $(51.13 \%)$ do not know that immunization can prevent their child from hepatitis B (Table 2).

Table 3. Knowledge of participants on diseases that can be prevented by immunization.

\begin{tabular}{lllll}
\hline \multirow{2}{*}{ Diseases } & Yes & \multicolumn{3}{l}{ No } \\
\cline { 2 - 5 } & Frequency & Percentage & Frequency & Percentage \\
\hline Cancer & 33 & $25.00 \%$ & 99 & $75.00 \%$ \\
Hepatitis & 65 & $48.87 \%$ & 68 & $51.13 \%$ \\
HIV & 29 & $22.14 \%$ & 102 & $77.86 \%$ \\
Measles & 82 & $61.65 \%$ & 51 & $38.35 \%$ \\
Malaria & 122 & $90.37 \%$ & 13 & $9.63 \%$ \\
Polio & 117 & $86.67 \%$ & 18 & $13.33 \%$ \\
Tetanus & 90 & $68.18 \%$ & 42 & $31.82 \%$ \\
Tuberculosis & 85 & $63.91 \%$ & 48 & $36.09 \%$ \\
Typhoid & 80 & $60.61 \%$ & 52 & $39.39 \%$ \\
Whooping cough & 103 & $77.44 \%$ & 30 & $22.56 \%$ \\
\hline
\end{tabular}

Association between Mothers'/Guides'Attitude and Sociodemographic Variables

Table 4 presents the chi-square analysis of the mothers'/guides' attitudes and their socio-demographic variables. Level of education and occupation are found to have statistically significant relationship with the attitude of the mothers/guides towards immunization $(\mathrm{P}<0.05)$

Table 4. Chi-Square analysis showing association between mothers'/guides' attitude towards immunization and socio-demographic characteristics of the respondents.

\begin{tabular}{llll}
\hline & $\boldsymbol{\chi}^{\mathbf{2}}$ value & Df & p value \\
\hline Age & 4.735 & 3 & 0.192 \\
Marital Status & 3.093 & 2 & 0.213 \\
Religion & 0.156 & 1 & 0.693 \\
Level of Education & 14.468 & 3 & $0.002 * *$ \\
Occupation & 27.711 & 4 & $0.000 * *$ \\
Number of Children & 9.804 & 7 & 0.200 \\
\hline
\end{tabular}

** Significant at $\mathrm{P}<0.05$ 
Association between Mothers'/Guides' Practices and Socio-demographic Variables

The association between the practices and the sociodemographic variables of the respondents is shown in table 5. Level of education, occupation and number of children were found to have statistically significant relationship with the practice of the mothers/guides on immunization $(\mathrm{P}<0.05)$

Table 5. Chi-Square analysis showing association between mothers'/guides' practice towards immunization and socio-demographic characteristics of the respondents.

\begin{tabular}{llll}
\hline & $\chi^{2}$ value & Df & p value \\
\hline Age & $5.719^{\mathrm{a}}$ & 3 & 0.126 \\
Marital Status & $2.193^{\mathrm{a}}$ & 2 & 0.334 \\
Religion & $1.149^{\mathrm{a}}$ & 1 & 0.284 \\
Level of Education & $24.398^{\mathrm{a}}$ & 3 & $0.000 * *$ \\
Occupation & $28.654^{\mathrm{a}}$ & 4 & $0.000 * *$ \\
Number of Children & $22.746^{\mathrm{a}}$ & 7 & $0.002 * *$ \\
\hline
\end{tabular}

** Significant at $\mathrm{P}<0.05$

FOCUS GROUP DISCUSSION (FGD)

WITH

VACCINATION HEALTH WORKERS (VHW)

Vaccination health worker knowledge on immunization schedule

Three vaccination health workers gave their consent to participate in the study but declined participation if their voice would be recorded on a record tape. Hence, a detailed note taking approach was adopted to take down their opinions. Tale 6 below shows the VHW knowledge on immunization schedule.

Table 6. Knowledge of vaccination health worker on Immunization schedule.

\begin{tabular}{|c|c|c|}
\hline Age & Vaccines & Notes \\
\hline \multirow[t]{4}{*}{ Birth } & BCG & $\begin{array}{l}\text { VHW reported that it can still be } \\
\text { given even if missed at birth but } \\
\text { child must be } \leq 11 \text { months }\end{array}$ \\
\hline & OPV & \\
\hline & Hep B & \\
\hline & OPV & \\
\hline \multirow[t]{2}{*}{6 weeks } & Penta & \\
\hline & PCV & \\
\hline \multirow{3}{*}{10 weeks } & OPV-2 & \\
\hline & Penta & \\
\hline & PCV & \\
\hline \multirow{4}{*}{14 weeks } & OPV & \\
\hline & Penta & \\
\hline & PCV & \\
\hline & IPV & \\
\hline 6 months & Vit A-1 & \\
\hline \multirow[b]{2}{*}{9 months } & Measles-1 & Can be given within 9-11 months. \\
\hline & $\begin{array}{l}\text { Yellow fever Men. } \\
\text { A }\end{array}$ & \\
\hline $12-15$ months & Vit A & \\
\hline
\end{tabular}

"Vaccination against Rotavirus is not available in our facility, even Men. A was just introduced about 3 months ago-(FGD)."

Missed opportunities and Under-utilization of Immunization

During the focus group discussion, the VHW reported that few of the mothers/guides that come to the Usman Dan Fodio
University teaching hospital miss the time of their child's vaccination. They reported that there has been a high compliance rate among the mothers/guides. Hence most of the mothers have been maximally utilizing the immunization service of the health facility.

"We usually carryout daily health education on the importance of immunization; breast feeding and hygiene talks before the start of immunization. This has made them always not wanting to miss their child's vaccination because they know the importance of immunization. Most of the mothers usually report that they love coming to our immunization clinic for their child's vaccination due to how we attend to them despite the availability of closer health centres to their homes - (FGD)."

Factors affecting the utilization of Immunization services

Participants of the FGD reported the following factors that affect the utilization of immunization services in the Usman dan Fodio Teaching Hospital immunization clinic.

1. Lack of consent from husband

2. Absence of mother/guide from town due to travelling

3. Travel cost to vaccination centre

4. Child's illness

5. Travel distance from home

"When i later see them and ask them why did they did not bring their child for vaccination, they will see that their husband must not know that they bring the child for vaccination and they only come when he is not at home or when he travelled - (FGD)."

"Some will tell us that they travelled that's why they did not bring the child for immunization, we usually tell them during our health education here that they should always travel with their child immunization card so that wherever they are they can go to any nearby health center and can receive immunization for their child - (FGD)."

"Some of them will tell us that they did not come because they don't have transport money to come for their children's immunization, we ask them that there are nearer immunization centres to their homes but they say they don't like going there because they don't like the way the vaccinators attend to them there - (FGD)."

\section{Discussion}

The result of the socio-demographic characteristics revealed that respondents within the age group of 21-30 had the highest participation $(60.14 \%)$ with only $2(1.45 \%)$ within the age group 41-50. Most respondents are married $(94.20 \%)$ and $80.4 \%$ practice Islam.

The dominant religion in this part of Nigeria is Islam hence the high number of respondents been Muslims. The number of those with no formal education is 57 (38.41\%) while those with formal education $82(59.42 \%)$. Among those with formal education, $47(57.31 \%)$ received formal education up to the tertiary level. This shows that a large proportion of the participants had a formal education. The occupation distribution showed that most respondents are house wives $49.2 \%, 26.09 \%$ are into different business 
activities, $14.49 \%$ are into teaching while $3.62 \%$ are into health-care. A high proportion of respondents that are house wives are those with no formal education. Respondents with at least two children $(27.5 \%)$ participated more in this study followed by those with three children $(25.4 \%)$. There is also an account of $2.9 \%$ of respondents having eight children and $4.3 \%$ having seven children. The high proportion of respondents with two children as revealed in this study is due to the fact that the younger age group make up the majority of the respondents, as the parity of a woman in this part of Nigeria continues to increase until menopause because child bearing is seen as a competition between women especially among women with same husband.

This study has been able to reveal that approximately $93 \%$ of the respondents have poor knowledge about immunization and only $7 \%$ has good knowledge about immunization despite the fact that a high number of the participants had a formal education even to the tertiary level. Although most of the respondents agree that immunization is important in protecting children from some infectious diseases but they could not appropriately differentiate between diseases that immunization protects against and those it doesn't. This finding is in consonance with the findings of Angadi et al, [12] in a study carried out in Bijapur City, Karnataka, India where the prevalence of limited knowledge of the mothers regarding immunization was identified. Similar studies by Manjunath et al, [13] also revealed that many mothers/guides are aware of the importance of immunization but specific information on the knowledge of vaccine preventable diseases are lacking. The result of this study regarding the knowledge of mothers/guides on immunization opposes the findings of Adefolalu et al, [14] which was carried out in South West of Nigeria who concluded that most mothers had good knowledge about immunization.

Fairly above half of the mothers/guides (57.97\%) display good attitudes towards immunization while $42.03 \%$ have poor attitudes towards immunization. This finding agrees with the study of Adefolalu et al, [14] that showed that mothers had positive attitudes towards immunization. Over half $(52.90 \%)$ displayed good practice towards immunization while $47.10 \%$ had poor practices towards immunization.

Approximately $62 \%$ and $61 \%$ of respondents in this study thought immunizing a child will prevent malaria fever and typhoid respectively. $51 \%$ do not think that immunization will prevent a child from hepatitis B. This finding is closely in tandem with the finding of a study by Awodele et al, [15] which reported that $48.6 \%$ of respondents thought a child can be vaccinated against malaria. Although there are reports on the development of malaria vaccines but this is yet to be included in routine immunization schedules.

It was observed in this study that the age and level of education of respondents had a statistical significant relationship with respondents' knowledge about immunization. This is similar to the study of Adefolalu et al, [14] reporting that maternal age, level of education and occupation are associated with respondents' knowledge about immunization. The level of education of mothers play a vital role in their knowledge about immunization and this in turn will influence compliance to immunization and ensuring complete child's vaccination.

Also this study revealed that the level of education, occupation and number of children have statistical significant relationship with the respondents attitudes and practices towards immunization. The findings of this study is contrary to the finding of Awodele et al, [15] that revealed that age also has significant association with attitude towards vaccination.

The focus group discussion held with the vaccination health workers showed that they had good knowledge on the immunization schedule. Rota vaccines are not available in the Usman dan Fodio teaching hospital immunization clinic and also through the focus group discussion it was revealed that the Meningitis Type A vaccine was just introduced three months ago. Despite the periodic incidence of meningococcal infection in this part of Nigeria for the past 200 years [16] there has been delay in introducing this vaccine in this part of Nigeria. In addition, this part of Nigeria has most times been ravaged by meningococcal infections other than type A but vaccines which immunize against this other types are not yet included in the routine immunization schedule available in this health institution. This finding corroborates the report by the Paediatric association in Nigeria, PAN [17] that since the commencement of the EPI in Nigeria in 1979, very limited number of 'new' vaccines has been added to the initial basic recommended number. This was seen in the introduction of Hepatitis B vaccine and Haemophilus Influenza b vaccine 22 years and 25 years respectively after the introduction of this vaccine in the global market.

This study revealed from the report of the vaccination health workers that mothers/guides have good compliance and utilization of immunization services but there are still cases of missed opportunities and under-utilization due to various factors which they raised. They are lack of husband's consent for the mother to take the child for immunization, absence of mother and child from town, sick child, travel cost and travel distance.

The women that do not have consent from their husbands only come for immunization when the husband is not around hence likelihood of under-utilizing immunization services, this is similar to the report by Antai el al, [18] in a study that children from families where the woman has no decision making power has the likelihood of not receiving full immunization.

A sick child deters the mother/guide from coming for immunization, this agrees with Kumar et al, [19] conclusion that illness of child is one of the major reasons mothers do not bring their child for immunization. Egondi et al, [7] also reported that sick guardian/sick child is also one of the factors that affect missed opportunities.

The effect of travel cost and travel distance on immunization from this study is contrary to Monguno [20] report that mothers' perceptions of distance were protective against under-immunization. 


\section{Conclusion}

According to the outcome of this study, it implies that a high proportion of mothers/guides have poor knowledge about immunization. This points at the fact that it is not just enough for mothers/guides to just know that immunization is important but efforts should be made to appropriately educate them on various vaccine preventable diseases and appropriate immunization schedules to ensure better compliance. Majority of the mothers/guides have good attitude and practices towards immunization. The socio-demographic characteristics such as level of education and maternal age are predicting factors that determine the mothers/guides knowledge about immunization while the attitudes and practice of mothers/guides towards immunization is affected by level of education, occupation and number of children. This study finding also revealed that factors such as lack of consent from husband, absence of mother/guide from town due to travelling, lack of transportation, attitude of vaccinators, child's illness, distance from home affects the utilization of child immunization services in Usman Dan Fodio University Teaching Hospital. It implies that information and awareness about immunization should not be targeted at women only but also men as they most time hold a vital position to ensure or negatively influence compliance to utilization of immunization services especially in homes or families where the woman has less or no decision autonomy.

\section{References}

[1] Ophori, E. A., Tula, M. Y., Azih, A. V., Okojie, R., \& Ikpo, P. E. (2014). Current trends of immunization in Nigeria: prospect and challenges. Tropical medicine and health, 42 (2), 67-75. doi: $10.2149 / \mathrm{tmh} .2013-13$.

[2] Orenstein, W. A., \& Ahmed, R. (2017). Simply put: Vaccination saves lives. Proceedings of the National Academy of Sciences of the United States of America, 114 (16), 40314033. doi: 10.1073/pnas.1704507114.

[3] Nasiru, S. G., Aliyu, G. G., Gasasira, A., Aliyu, M. H., Zubair, M., Mandawari, S. U., Waziri, H., Nasidi, A., \& El-Kamary, S S. (2012). Breaking community barriers to polio vaccination in Northern Nigeria: the impact of a grass roots mobilization campaign (Majigi). Pathogens and global health, 106 (3), 166-171. https://doi.org/10.1179/2047773212Y.0000000018

[4] World Health Organization. Immunization, vaccines and biologicals. Global routine vaccination coverage 2011. Published in the Weekly Epidemiological Record on 2 November 2012.

[5] Public Health Agency of Canada. Canadian immunization guide: seventh edition-2006. Available at: www.phacaspc.gc.ca/publicat/cig-gci/index-eng.php. Accessed August $20,2010$.

[6] Joan Gilmour, Christine Harrison, Leyla Asadi, Michael H. Cohen and Sunita Vohra. Childhood Immunization: When Physicians and Parents Disagree. Pediatrics November 2011,
128 (Supplement 4) S167-S174; DOI: https://doi.org/10.1542/peds.2010-2720E.

[7] Egondi, T., Oyolola, M., Mutua, M. K., \& Elung'ata, P. (2015). Determinants of immunization inequality among urban poor children: evidence from Nairobi's informal settlements. International journal for equity in health, 14, 24. https://doi.org/10.1186/s12939-015-0154-2.

[8] Pielak K L., Mcintyre C. C., Tu A. W., Remple V. P., Halperin B. \& Buxton J. A. (2010) Identifying attitudes, beliefs and reported practices of nurses and doctors as immunization providers. Journal of Advanced Nursing 66 (7), $1602-1611$

[9] Dionne M, Boulianne N, Duval B, Lavoie F, Laflamme N, Carsley J, Valiquette L, Gagnon S, Rochette L, De Serres G 2001. Lack of conviction about vaccination in certain Quebec vaccinators. Canadian Journal of Public Health $=$ Revue Canadienne de Sante Publique [01 Mar 2001, 92 (2): 100-104]

[10] Leask J, Quinn HE, Macartney K, Trent M, Massey P, Carr C, Turahui J. (2008). Immunisation attitudes, knowledge and practices of health professionals in regional NSW. Australian and New Zealand Journal of Public Health [01 Jun 2008, 32 (3): 224-229].

[11] Nicole Boulianne, Bernard Duval, Gaston De Serres, et al., "Opinions of Quebec Parents and Vaccinators on the Usefulness of Chickenpox Vaccine," Canadian Journal of Infectious Diseases, vol. 12, no. 3, pp. 153-156, 2001. https://doi.org/10.1155/2001/948478.

[12] Angadi, M. M., Jose, A. P., Udgiri, R., Masali, K. A., \& Sorganvi, V. (2013). A study of knowledge, attitude and practices on immunization of children in urban slums of bijapur city, karnataka, India. Journal of clinical and diagnostic research: JCDR, 7 (12), 2803-2806. doi: $10.7860 / \mathrm{JCDR} / 2013 / 6565.3763$.

[13] Manjunath, Usha \& Pareek, R P. (2003). Maternal Knowledge and Perceptions about the Routine Immunization Programme -A study in a semi urban area in Rajasthan. Indian Journal of Medical Sciences. Vol. 57, No. 4. 158-163.

[14] Adefolalu OA, Kanma-Okafor OJ, Balogun MR. Maternal Knowledge, attitude and compliance regarding immunization of under five children in Primary Health Centres in Ikorodu Local Government Are, Lagos State. Journal of Clinical Science 2019; 16: 7-14.

[15] Awodele O, Oreagba I. A, Akinyede A, Awodele D. F, Dolapo D, C. The Knowledge and attitude towards childhood immunization among mothers attending antenatal clinic in Lagos University Teaching Hospital, Nigeria. Tanzania Journal of Health Research, Vol 12, No 3, 2010.

[16] Balarabe S. A. (2018). Epidemics of meningococcal meningitis in Northern Nigeria focus on preventive measures. Annals of African medicine, 17 (4), 163-167. doi: 10.4103/aam.aam_62_17.

[17] PAN Advisory Committee on Immunisation. Paediatric Association of Nigeria (PAN) recommended routine immunization schedule for Nigerian children. DOI: http://dx.doi.org/10.4314/njp.v39i4.1 Accepted: 9th May 2012

[18] Antai D. Gender inequities, relationship power, and childhood immunization uptake in Nigeria: a population-based crosssectional study. Int J Infect Dis. 2012; 16 (2): e136-45. doi: 10.1016/j.ijid.2011.11.004. 
[19] Kumar, Chandan \& Devi, Rajkumari \& Choudhary, Atul \& Pugazhendi, Prof Sanchita \& Pundir, Namrata. (2017). Factors Influencing Utilization of Immunization Services and Effectiveness of a Guided Health Action on Immunization Status among Parents of Under Fives in a Selected Area of Dehradun, Uttarakhand. 10.21088/cphn.2455.8621.2117.1.
[20] Monguno A. K. (2013). Socio Cultural and Geographical Determinants of Child Immunisation in Borno State, Nigeria. Journal of public health in Africa, 4 (1), e10. doi: 10.4081/jphia.2013.e10. 